\title{
Helping Children Cope with Violence and Trauma
}

\section{A School-Based Program That Works}

RAND RESEARCH AREAS

CHILDREN AND FAMILIES EDUCATION AND THE ARTS ENERGY AND ENVIRONMENT HEALTH AND HEALTH CARE INFRASTRUCTURE AND TRANSPORTATION INTERNATIONAL AFFAIRS LAW AND BUSINESS NATIONAL SECURITY POPULATION AND AGING PUBLIC SAFETY

SCIENCE AND TECHNOLOGY TERRORISM AND HOMELAND SECURITY
This product is part of the RAND Corporation research brief series. RAND research briefs present policy-oriented summaries of published, peer-reviewed documents.

Corporate Headquarters 1776 Main Street P.O. Box 2138 Santa Monica, California 90407-2138 TEL 310.393 .0411 FAX 310.393 .4818

(C) RAND 2011
V iolence is one of our most significant public health issues. Between 20 percent and 50 percent of children in the United States are touched by violence, either as victims or, even more commonly, as witnesses. Even more are exposed to natural disasters, accidents, and traumatic losses. The emotional impact may be profound. Children exposed to violence frequently develop post-traumatic stress symptoms. They are more likely to have behavioral problems, poorer school performance, more days of school absence, and feelings of depression and anxiety. Violence affects all racial, ethnic, and economic groups, but its burden falls disproportionately on poor and minority children-the very children whose mental health needs are least likely to be met by the health care system. School officials are often willing to provide help at school. But these professionals face an important question: What works? Until recently, there was no evidence base for determining the effectiveness of interventions to address these problems.

To fill this gap, a team of clinician-researchers from several institutions collaborated to develop, implement, and evaluate an intervention designed to help children traumatized by violence. The team included professionals from the RAND Corporation, the University of California, Los Angeles (UCLA), and the Los Angeles Unified School District (LAUSD) and has expanded over time to include colleagues at the University of Southern California and many community partners.

The program works. Students who participated in the program had significantly fewer post-traumatic stress symptoms, less depression, and less psychosocial dysfunction. The program was implemented successfully by school-based mental health clinicians. The participating schools, located in economically disadvantaged neighborhoods, have a large percentage of Latino students, demonstrating the program's ability to

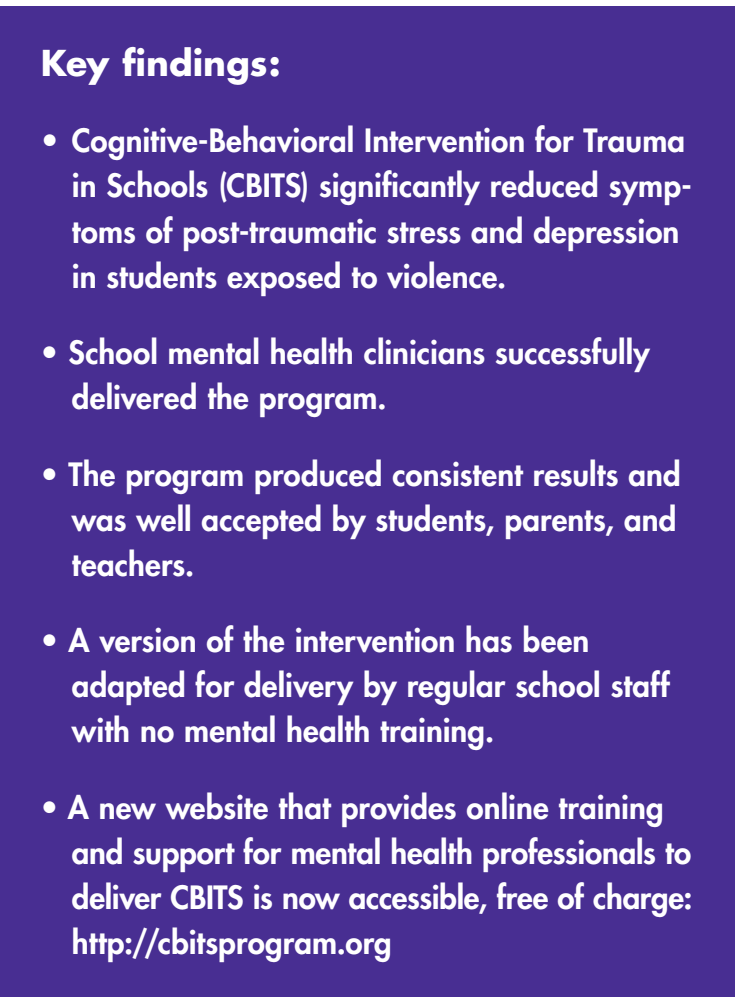

reach poor and minority children. And the program was welcomed by students, teachers, school officials, and parents.

\section{The First Randomized Controlled Study of a School Program to Help Children Traumatized by Violence}

RAND, UCLA, and LAUSD began to collaborate in 1998 to conduct studies to determine the magnitude of violence exposure and post-traumatic stress symptoms among LAUSD schoolchildren and to develop effective interventions. The team developed and implemented an earlier program designed specifically for immigrant children, many of whom are subjected to violence in their country of origin, during their immigration to the United States, and/or after their arrival (often to 
a disadvantaged neighborhood). Building on the earlier work, the team designed and conducted a randomized controlled study in the 2000-2001 academic year. Students in the study attended one of two Los Angeles public middle schools in largely Latino neighborhoods. Psychiatric social workers from LAUSD administered a screening questionnaire to English-speaking sixth-grade students in the two schools. Students were eligible to participate in the program if they (1) had substantial direct exposure to violence, (2) had post-traumatic stress symptoms in the clinical range (a score of 14 or higher on the Child Post-Traumatic Stress Symptom Scale [CPSS]), and (3) were willing to discuss their symptoms in a group setting. Participants experienced a range of violence, from witnessing serious physical fights to being attacked with a knife or gun. A total of 159 students were eligible to participate; 126 actually participated (the parents of 28 children did not give consent, and five children elected not to participate). All 126 students completed the baseline assessments, 93 percent completed a three-month follow-up, and 90 percent completed both the three-month and the sixmonth follow-ups.

Students were randomly assigned to two groups. One group (the early-intervention group) started the program promptly; the other (the late-intervention group) was waitlisted for later in the school year. The intervention program, called the Cognitive-Behavioral Intervention for Trauma in Schools (CBITS), was developed at RAND in close collaboration with mental health clinicians at LAUSD. It consists of ten group sessions designed for inner-city schools with a multicultural population. Activities include training children in relaxation; dealing with negative thoughts; solving real-life problems; approaching anxiety-provoking situations; and coping with the violent event through talking, drawing pictures, and writing. The program is also designed to build both peer and parental support. In addition to the group sessions, the program included at least one individual session for each child, four group parenting meetings, and an educational presentation for teachers. The LAUSD school clinicians who delivered the program received two days of training and weekly supervision from the other members of the research team. To help ensure that the program was standardized, the clinicians followed the CBITS treatment manual (see the text box).

\section{Participants Experienced Significant Mental Health Improvement}

Data from students, parents, and teachers were collected at baseline, three months, and six months. These intervals enabled both early- and late-intervention groups to complete the program and to be tested in the same academic year.

Baseline: The 126 students enrolled in the program had substantial levels of exposure to violence. On average, students reported being a victim of 2.8 violent events and directly witnessing 5.9 violent events in the previous year. The mean CPSS score was 24, indicating moderate to severe posttraumatic stress symptoms. There were no significant differences between the early-intervention and late-intervention groups at the start of the program.

Three months: At three months, students in the earlyintervention group had completed the program; students in the late-intervention group had not yet begun. Figure 1 compares the CPSS scores for the two groups. The earlyintervention students showed substantial improvement. The magnitude of the difference between the two groups means that 86 percent of the early-intervention group reported lesssevere post-traumatic stress symptoms than would have been expected without intervention. Figure 2 shows depressive symptom scores; the magnitude of the difference between the two groups means that 67 percent of the early-intervention group reported less-severe symptoms than would have been

\section{Cognitive-Behavioral Intervention for Trauma in Schools (CBITS) Session Outline}

Session 1: Introduction of group members, confidentiality, and group procedures; explanation of treatment using stories; discussion of reasons for participation (kinds of stress or trauma).

Session 2: Education about common reactions to stress or trauma, relaxation training to combat anxiety.

Individual Session: Between sessions 2 and 6.

Session 3: Thoughts and feelings (introduction to cognitive therapy), "fear thermometer," linkage between thoughts and feelings, combating negative thoughts.

Session 4: Combating negative thoughts.

Session 5: Avoidance and coping (introduction to reallife exposure), construction of fear hierarchy, alternative coping strategies.

Sessions 6 and 7: Exposure to stress or trauma memory through imagination, drawing, and writing.

Session 8: Introduction to social problem solving.

Session 9: Practice with social problem solving and hot seat.

Session 10: Relapse prevention and graduation ceremony.

SOURCE: Jaycox LH, Cognitive-Behavioral Intervention for Trauma in Schools, Longmont, Colo.: Sopris West Educational Services, 2003. 
Figure 1

Post-Traumatic Stress Symptoms at Baseline, Three Months, and Six Months

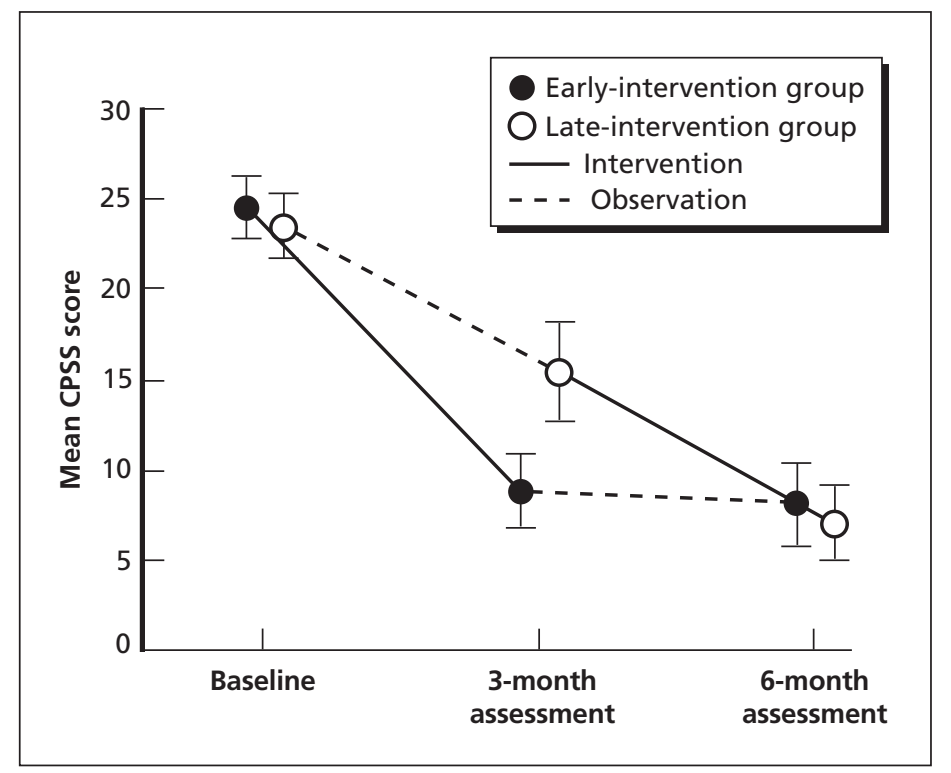

Figure 2

Depressive Symptoms at Baseline, Three Months, and Six Months

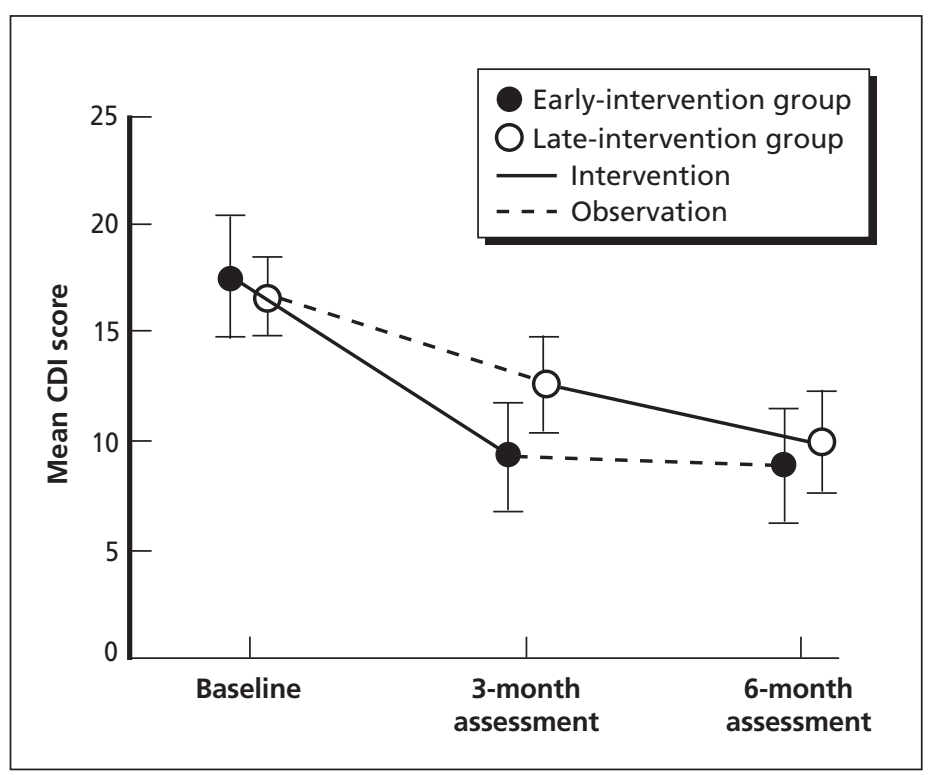

SOURCE: Stein BD, Jaycox LH, Kataoka SH, Wong M, Tu W, Elliott MN, and Fink A, "A Mental Health Intervention for School Children Exposed to Violence," Journal of the American Medical Association, Vol. 290, No. 6, August 6, 2003, pp. 603-611. Copyright @ 2003, American Medical Association. All rights reserved.

NOTE: $\mathrm{CDI}=$ Children's Depression Inventory, an assessment tool and scale for measuring child depression.

expected without intervention. In addition, parents of students in the early-intervention group reported that their children were functioning significantly better.

Six months: At six months, both groups had completed the program. The group that received CBITS after the waiting period also showed substantial improvement in symptoms, and the group that had received CBITS earlier maintained their gains.

\section{Classroom Behavior Stayed About the Same}

Teachers assessed each student's shyness and anxiety, learning skills, and acting-out behavior in the classroom. Teachers observed only slight improvements throughout the study period. Possible explanations include the following: A student's classroom behavior is affected by many factors, not just the child's mental health; there may be a time lag before improved mental health translates into improved behavior; teachers may be more attuned to disruptive behavior than to anxiety or depression; or perhaps the program simply does not affect classroom behavior.

\section{SSET: A Version of CBITS for Nonclinical School Personnel}

As the CBITS program began to be disseminated nationally, the CBITS research team sought feedback from teachers, school counselors, clinicians, and national experts on how to make their program easier for schools to implement. The result was an adaptation of CBITS: Support for Students Exposed to Trauma (SSET). SSET keeps the same cognitivebehavioral approach and ten group-session structure as CBITS, but the clinical aspects of the original program have been modified to allow them to be used by teachers and other nonclinicians. Changes include the following:

- Instructors use the lesson-plan format familiar to teachers.

- Individual student sessions and optional parent sessions are eliminated.

- Students draw or write about their traumatic experiences rather than recounting them one-on-one with a counselor.

SSET Pilot Test. Beginning in 2005, SSET was pilottested for two years in two Los Angeles middle schools, one in the San Fernando Valley and the other in South Central Los Angeles. Most of the students were Latino and came from lower socioeconomic backgrounds, and more than half were English learners. Of the students screened for participation in SSET, 58 percent met the initial study criteria: They had experienced symptoms of post-traumatic stress disorder (PTSD). The final pilot test sample consisted of 76 students with appropriate parental and student consent to participate in the study. Three teachers and one school counselor 
without any specific mental health clinical background were trained to deliver SSET. Each of the four instructors led four SSET groups; each group met once a week during the school day and received a total of ten lessons. Half of the students were given SSET immediately, while the start of the other half was delayed until the first intervention group had ended. The latter group of students served as controls.

Students were surveyed to measure their trauma symptoms at baseline, at three months after the first group had completed SSET, and at six months after the control group had completed the program. Additional assessments focused on the instructors' ability to faithfully deliver quality SSET lessons. Both students' parents and teachers were surveyed about the students' behavior at home and at school, and students were surveyed about their own symptoms and behaviors.

Promising Results. Even in this small pilot test, the results indicate that SSET can be implemented successfully by teachers and school counselors without mental health training to address violence-related PTSD and depression, especially in low-income, urban students. The pilot test results showed that, overall, students showed small reductions in trauma symptoms, with those having a high level of symptoms before taking SSET benefiting the most. In addition, both students and parents reported good-to-high satisfaction with the program. Teachers reported small improvements in student behavior, although parents did not.

\section{A CBITS Dissemination Website: Making CBITS Training More Accessible}

In March 2011, the CBITS team made CBITS training materials available online. Districts and schools now have the option of in-person or online training for mental health professionals who intend to deliver CBITS. The program's website (http://cbitsprogram.org/) allows mental health professionals to register free of charge for an online CBITS course to support training. The site also provides additional support resources, including a discussion board, an ask-theexpert feature, quick tips, and implementation materials.

\section{Conclusions}

Extensive research since 2000 has supported the team's initial study results: CBITS has significantly helped students cope with the devastating effects of violence. Students who participate in the program report fewer symptoms of posttraumatic stress, depression, and psychosocial dysfunction. CBITS is now recognized as a recommended practice by several national agencies that assess the quality of mental health interventions, including the Centers for Disease Control and Prevention's Prevention Research Center, the Substance Abuse

\section{CBITS Update}

The new CBITS training website is available for mental health professionals interested in learning to deliver the CBITS intervention: http://cbitsprogram.org

The CBITS manual is available from Cambium Learning: http://store.cambiumlearning.com

CBITS was used successfully to help children who were affected by Hurricane Katrina with post-traumatic stress symptoms.

Adaptations and materials are available for special populations, including students in foster care and special education.

Work is ongoing to study different ways to disseminate programs like CBITS to schools.

CBITS resources are disseminated through the Trauma Services Adaptation Center for Schools and Communities, part of the National Child Traumatic Stress Network.

The RAND CBITS website includes a list of CBITS and SSET publications; information about user products, including program manuals; and related links: http://www.rand.org/health/projects/cbits.html

and Mental Health Services Administration's (SAMHSA's) National Registry of Evidence-Based Programs and Practices, and the U.S. Department of Justice's Office of Juvenile Justice and Delinquency Prevention.

CBITS has been implemented widely across the United States and abroad and is also being actively disseminated through SAMHSA's National Child Traumatic Stress Network. Since 2001, the CBITS team has supported use in several states in the United States and in other countries, including

- California, Colorado, the District of Columbia, Illinois, Louisiana, Maryland, Mississippi, Missouri, Montana, New Jersey, New Mexico, Tennessee, Washington, and Wisconsin

- Australia, China, Guyana, and Japan.

The program is designed to build resilience and coping skills, so it is possible that the short-term effects identified by research will be lasting. The team hopes that the program will form the basis of continuing efforts to provide long-term help to victims of violence. 


\section{This research highlight summarizes RAND Health research reported in the following publications:}

Stein BD, Kataoka S, Jaycox LH, Wong M, Fink A, Escudero P, and Zaragoza C, "Theoretical Basis and Program Design of a School-Based Mental Health Intervention for Traumatized Immigrant Children: A Collaborative Research Model," Journal of Behavioral Health Services and Research, Vol. 29, No. 3, August 2002, pp. 318-326.

Jaycox L, Stein BD, Kataoka S, Wong M, Fink A, Escudero P, Tu W, and Zaragoza C, "Violence Exposure, Posttraumatic Stress Disorder, and Depressive Symptoms Among Recent Immigrant Schoolchildren," Journal of the American Academy of Child and Adolescent Psychiatry, Vol. 41, No. 9, September 2002, pp. 1104-1110.

Jaycox LH, Cognitive-Behavioral Intervention for Trauma in Schools, Longmont, Colo.: Sopris West Educational Services, 2003.

Kataoka S, Stein BD, Jaycox LH, Wong M, Escudero P, Tu W, Zaragoza C, and Fink A, "A School-Based Mental Health Program for Traumatized Latino Immigrant Children," Journal of the American Academy of Child and Adolescent Psychiatry, Vol. 42, No. 3, March 2003, pp. 311-318.

Stein BD, Jaycox LH, Kataoka SH, Wong M, Tu W, Elliott MN, and Fink A, "A Mental Health Intervention for School Children Exposed to Violence," Journal of the American Medical Association, Vol. 290, No. 6, August 6, 2003, pp. 603-611.

Jaycox LH, Kataoka SH, Stein BD, Wong M, and Langley A, "Responding to the Needs of the Community: A Stepped Care Approach to Implementing Trauma-Focused Interventions in Schools," Report on Emotional and Behavioral Disorders in Youth, Vol. 5, No. 4, 2005, pp. 85-88, 100-103.

Kataoka SH, Fuentes S, O’Donoghue V, Castillo-Campos P, Bonilla A, Halsey K, Avila JL, and Wells KB, "A Community Participatory Research Partnership: The Development of a Faith-Based Intervention for Children Exposed to Violence," Ethnicity \& Disease, Vol. 16 (Supplement), Winter 2006, pp. S89-S97.

Ngo V, Langley A, Kataoka S, Nadeem E, Escudero P, and Stein BD, "Providing Evidence-Based Practice to Ethnically Diverse Youths: Examples from the Cognitive Behavioral Intervention for Trauma in Schools (CBITS) Program," Journal of the American Academy of Child and Adolescent Psychiatry, Vol. 47, No. 8, August 2008, pp. 858-862.

Jaycox LH, Langley A, and Dean KL, Support for Students Exposed to Trauma: The SSET Program, Santa Monica, Calif.: RAND Corporation, TR-675-NIMH, 2009. As of April 14, 2011:

http://www.rand.org/pubs/technical_reports/TR675.html

Cohen JA, Jaycox LH, Mannarino AP, Walker DW, Langley AK, and DuClos J, “Treating Traumatized Children After Hurricane Katrina: Project Fleur-de-Lis," Clinical Child and Family Psychology Review, Vol. 12, No. 1, March 2009, pp. 55-64.

Jaycox LH, Langley AK, Stein BD, Wong M, Sharma P, Scott M, and Schonlau M, "Support for Students Exposed to Trauma: A Pilot Study," School Mental Health, Vol. 1, No. 2, June 2009, pp. 49-60.

Jaycox LH, Cohen JA, Mannarino AP, Walker DW, Langley AK, Gegenheimer KL, Scott M, and Schonlau M, "Children's Mental Health Care Following Hurricane Katrina: A Field Trial of Trauma-Focused Psychotherapies," Journal of Traumatic Stress, Vol. 23, No. 2, April 2010, pp. 223-231.

Langley AK, Nadeem E, Kataoka SH, Stein BD, and Jaycox LH, "Evidence-Based Mental Health Programs in Schools: Barriers and Facilita-

tors of Successful Implementation,” School Mental Health, Vol. 2, No. 3, September 2010, pp. 105-113. 
Abstracts of all RAND Health publications and full text of many research documents can be found on the RAND Health website at www.rand.org/health. The RAND Corporation is a nonprofit institution that helps improve policy and decisionmaking through research and analysis. RAND's publications do not necessarily reflect the opinions of its research clients and sponsors. RAND ${ }^{\circledR}$ is a registered trademark.

RAND Offices

Santa Monica, CA • Washington, DC • Pittsburgh, PA • New Orleans, LA/Jackson, MS • Boston, MA • Doha, QA • Abu Dhabi, AE • Cambridge, UK • Brussels, BE 


\section{RAND HEALTH}

CHILDREN AND FAMILIES

EDUCATION AND THE ARTS

ENERGY AND ENVIRONMENT

HEALTH AND HEALTH CARE

INFRASTRUCTURE AND

TRANSPORTATION

INTERNATIONAL AFFAIRS

LAW AND BUSINESS

NATIONAL SECURITY

POPULATION AND AGING

PUBLIC SAFETY

SCIENCE AND TECHNOLOGY

TERRORISM AND HOMELAND SECURITY
The RAND Corporation is a nonprofit institution that helps improve policy and decisionmaking through research and analysis.

This electronic document was made available from www.rand.org as a public service of the RAND Corporation.

\section{Support RAND}

Browse Reports \& Bookstore

Make a charitable contribution

\section{For More Information}

Visit RAND at www.rand.org

Explore RAND Health

View document details

\section{Research Brief}

This product is part of the RAND Corporation research brief series. RAND research briefs present policy-oriented summaries of individual published, peer-reviewed documents or of a body of published work.

\section{Limited Electronic Distribution Rights}

This document and trademark $(s)$ contained herein are protected by law as indicated in a notice appearing later in this work. This electronic representation of RAND intellectual property is provided for noncommercial use only. Unauthorized posting of RAND electronic documents to a non-RAND website is prohibited. RAND electronic documents are protected under copyright law. Permission is required from RAND to reproduce, or reuse in another form, any of our research documents for commercial use. For information on reprint and linking permissions, please see RAND Permissions. 